\title{
Early Outcomes after Cardiac Surgery in Neonates and Infants in India
}

\author{
Shashi RaJ ${ }^{1 *}$ AND Sethuraman Swaminathan ${ }^{2}$ \\ ${ }^{1}$ Pediatric and Adult CHD Heart Transplantation, Narayana Hrudayalaya, Bangalore, India; and ${ }^{2}$ Division of Pediatric Cardiology, \\ Department of Pediatrics, University of Miami, Miller School of Medicine, Miami, Florida 33136, United States. \\ *drshashiraj@gmail.com
}

$\mathrm{T}$ he clinical landscape and outlook of critical congenital heart disease (CHD) and its management has been steadily advancing over the past three decades all over the world. India is not far behind in this race for betterment of care for the neonates and infants with CHD. As we step into the third decade of this millennium, the overall survival rate of many forms of CHD have improved. Critical CHD is generally defined as structural heart defects that are present at birth, and which require surgical or trans-catheter intervention either as a neonate or during the first year of life. Globally, CHDs are present in about 8-10 per 1000 live births. Among this group, critical CHDs account for nearly $25 \%$ [1,2]. The combination of good clinical examination after birth along with institution of the inexpensive universal pulse oximetry screening of neonates in the hospitals before discharge have resulted in increased identification of these major CHDs. Some of the critical CHDs diagnosed after birth with such screening include transposition of the great arteries, tetralogy of Fallot, pulmonary atresia, tricuspid atresia, total anomalous pulmonary venous return, truncus arteriosus, double outlet right ventricle, and left heart obstructive lesions such as critical coarctation and hypoplastic left heart syndrome.

In a recent large retrospective population-based cohort study in infants born with CHDs, covering nearly three decades, the 1-year survival for infants with critical CHDs was noted to improve from $67.4 \%$ in 1980 s to $82.5 \%$ in early 2000s [1]. Advances in fetal cardiac imaging, widespread adoption of CHD screening as mentioned above along with improved perioperative critical care have all contributed to early diagnosis of critical CHD and prompt management. This has in turn led to better survival and outcomes in this vulnerable population. However, early and late outcomes of newborns with CHDs still largely depend on the individual characteristics of the lesion and its pathophysiology. In addition, other co-morbidities such as intrauterine growth restriction, genetic syndromes, malnutrition etc, have strong influence on the surgical results and overall survival in critical CHD. Current evidence supports improved surgical outcomes among newborns with critical CHDs operated in large volume surgical centers. This could be a result of multidisciplinary coordinated care with 24 hour access to advanced resources and expertise (extra corporeal membrane oxygenation (ECMO) support, availability of non-cardiac neonatal surgical specialties, advanced imaging, etc) [3]. Continued refinement of trans-catheter interventional procedures such as ductal stenting and right ventricular outflow tract stenting performed in neonates and infants have offered non-surgical palliative alternatives and has resulted in reduced morbidity and mortality in specific lesions (eg, duct-dependent pulmonary blood flow lesions like tetralogy of Fallot, pulmonary atresia) $[4,5]$.

Even though all major metropolitan cities and a vast number of tier-2 cities in India have centers offering advanced care for critical CHD, a national level pediatric cardiac surgery registry is not present. As a result, currently in India, total pediatric cardiac surgical volumes and clinical outcomes remain speculative. In a study of 330 consecutive neonates in a tertiary care center in India, the overall mortality for all neonatal corrective and palliative cardiac surgical procedures was 8.8\% [6]. However, many high risk lesions such as hypoplastic left heart syndrome and severe Ebstein anomaly were excluded in that study. In another study, early extubation in infants after cardiac surgery lowered pediatric intensive care unit (ICU) stay and sepsis, without increasing mortality or reintubation rate [7]. In a large multicenter multinational study of more than 2100 children who underwent tetralogy of Fallot (most common cyanotic congenital heart disease) repair, involving 32 centers across 20 low- and middle-income countries, older age at surgery was not a risk factor for death (overall mortality of 3.6\%). However, nutritional status and severity of hypoxemia were significantly associated with higher postoperative infection and mortality rates [8].

In this issue of Indian Pediatrics, Shukla, et al. [9] have evaluated the outcomes of cardiac surgeries in neonates and infants in India. In this retrospective study 
done at a tertiary care center over a 7-year period, 200 neonates with high complexity CHDs (Risk Adjustment in Congenital Heart Surgery (RACHS-1) median score of 4) underwent cardiac surgeries. The authors report an overall mortality rate of $13.5 \%$ (27/200 patients). Despite the limitations of a retrospective study design, this analysis of a robust number of study subjects shows that the mortality in this population after cardiac surgery was independently predicted by the presence of preoperative shock, duration of mechanical ventilation, residual lesions after surgery, and cardiopulmonary bypass time. The conclusions in this study highlight the important factors that may affect the overall outcome of pediatric cardiac surgery in India. These include prompt recognition and appropriate referral of critical CHDs in neonates and infants, universal access to quality tertiary care, and appropriate utilization of finite resources and expertise.With these efforts, the overall morbidity and mortality in infants with critical CHD will continue to improve in the coming decades in India.

Funding: None; Competing interests: None stated.

\section{REFERENCES}

1. Oster ME, Lee KA, Honein MA, Riehle-Colarusso T, Shin M, Correa A. Temporal trends in survival among infants with critical congenital heart defects. Pediatrics. 2013;131:e1502-8.
2. Saxena A, Mehta A, Sharma M, Salhan S, Kalaivani M, Ramakrishnan S, et al. Birth prevalence of congenital heart disease: A cross sectional observational study from North India. Ann Pediatr Cardiol. 2016; 9:205-9.

3. Kansy A, ZuEulenburg C, Sarris G, Jacobs JP, Fragata $\mathrm{J}$, Tobota $\mathrm{Z}$, et al. Higher programmatic volume in neonatal heart surgery is associated with lower early mortality. Ann Thorac Surg. 2018; 105:1436-40.

4. Khalil M, Jux C, Rueblinger L, Behrje J, Esmaeili A, Schranz D. Acute therapy of newborns with critical congenital heart disease. Transl Pediatr. 2019;8:114-26.

5. Savla JJ, Faerber JA, Huang YV, Zaoutis T, Goldmuntz E, Kawut SM, et al. 2-year outcomes after complete or staged procedure for tetralogy of Fallot in neonates. J Am Coll Cardiol. 2019; 74:1570-9.

6. Bakshi KD, Vaidyanathan B, Sundaram KR, Roth SJ, Shivaprakasha K, Rao SG, et al. Determinants of early outcome after neonatal cardiac surgery in a developing country. J Thorac Cardiovasc Surg. 2007; 134:765-71.

7. Alam S, Shalini A, Hegde RG, Mazahir R, Jain A Predictors and outcome of early extubation in infants postcardiac surgery: A single-center observational study. Ann Card Anaesth. 2018; 21:402-6.

8. Sandoval N, Carreno M, Novick WM, Agarwal R, Ahmed I, Balachandran $\mathrm{R}$ et al. Tetralogy of Fallot repair in developing countries: International quality improvement collaborative. Ann Thorac Surg. 2018; 106:1446-51.

9. Shukla VV, Bobhate P, Mohanty S, Rao S, Joshi P, Joshi V. Early outcomes of neonatal cardiac surgery in India. Indian Pediatr. 2020;57:129-32. 